
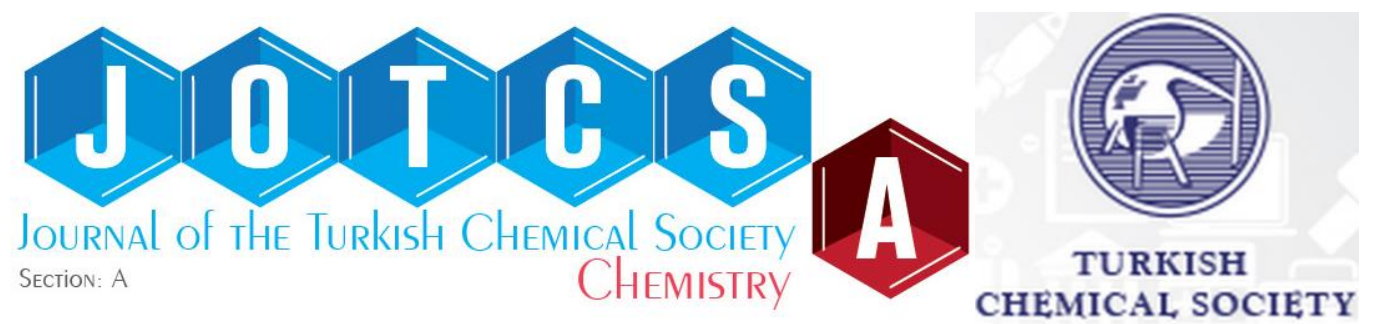

\title{
Supercritical Carbondioxide Extraction of Lavandula Officinalis (Lavender) and Hypericum Perforatum (Centaury) Plants Grown in Mersin Region: Investigation of Antioxidant and Antibacterial Activities of Extracts and Usage as Cosmetic Preservatives in Creams
}

\section{Göktürk AVŞAR ${ }^{1}$, Derya YÜKSEL1 ${ }^{1}$, Fatih Mehmet EMEN² $\square$, Tuncay YEŞILKAYNAK ${ }^{4}$, Levent KAHRIMAN 5}

\author{
${ }^{1}$ Mersin University, Faculty of Science and Letters, Department of Chemistry, Mersin, TURKEY \\ ${ }^{2}$ Mehmet Akif Ersoy University, Faculty of Arts and Sciences, Department of Chemistry, Burdur, TURKEY \\ ${ }^{3}$ Çankırı Karatekin University, Faculty of Science, Department of Chemistry, Çankırı, TURKEY \\ ${ }^{4}$ Department of Chemistry Technology, Afsin Vocational School, Sütcü Imam University, Kahramanmaras, \\ TURKEY \\ 5Laber Organic Cosmetics R \& D Production, Marketing, Industry Trade Co., İzmir, TURKEY
}

Abstract: The extraction of Lavandula Officinalis (lavender) and Hypericum Perforatum (centaury) plants grown in Mersin region were extracted by supercritical carbon dioxide extraction system ( $P=100$ bar, $T=40$ $\left.{ }^{\circ} \mathrm{C}\right)$. The chemical compositions of the lavender and centaury extracts were analyzed by Gas Chromatography-Mass Spectrometry (GC-MS). For antioxidant activity experiments, 1,1-diphenyl-2picrylhidrazine (DPPH) radical was used in radical effect tests. For antimicrobial activity studies, Bacillus subtilis, Klebsiella pneumoniae, Escherichia coli, Staphylococcus aureus, Pseudomonas aeruginosa and Streptococcus pneumoniae with Nutrient Agar Broth (NA) and Eosin Methylene-blue lactose sucrose agar (EMB) broth were used. For determining antimicrobial effect of plant extracts, diffusion method was used. Antibacterial and antioxidant properties of the obtained extracts were examined and have been determined that the resulting extracts have significant antioxidant and antimicrobial effects. The extracts were also used in cosmetic cream formulas as protectives. Effective results have also been determined in antibacterial activity studies of creams after 6 months.

Keywords: Supercritical carbon dioxide extraction, Lavandula officinalis (lavender), Hypericum perforatum (centaury), antioxidant, antibacterial, DPPH, preservatives

Submitted: October 01, 2018. Accepted: October 20, 2018.

Cite this: Avşar G, Yüksel D, Emen F, Demirdöğen R, Yeşilkaynak T, Kahrıman L. Supercritical Carbondioxide Extraction of Lavandula Officinalis (Lavender) and Hypericum Perforatum (Centaury) Plants Grown in Mersin Region: Investigation of Antioxidant and Antibacterial Activities of Extracts and Usage as Cosmetic Preservatives in Creams. JOTCSA. 2018;5(3):1215-20.

DOI: http://dx.doi.org/10.18596/jotcsa.466279.

*Corresponding author. E-mail: gokturkavsar@yahoo.com

\section{INTRODUCTION}

Plants are one of the most essential fundamental resources of life ever since the beginning of human kind because of their useful bioactive compounds such as lipids, phytochemicals, pharmaceutics, flavors, fragrances, and pigments. Oils and extracts of plants are still being used in many applications such as food preservation, cosmetics, pharmaceuticals, alternative medicine and natural therapies. Plant oils and extracts can be used to prevent the formation of microorganisms that cause many diseases and they also provide protection against pathogenic bacteria that pose a threat to human health due to their antioxidant and antibacterial properties. Previous studies have shown that there is a correlation between antioxidant from plants and oxidative stress and age-dependent diseases (1-5). 
Turkey is one of the leading countries in plant trade with its geographical place, climate and plant variety, agricultural potential, and wide surface area. Especially, Mersin region is a commercially important location due to the plant variety. In addition, Mersin has a significant share in plant trading with about $60 \%$ of plants in Turkey. Lavandula officinalis (Lavender) and Hypericum perforatum (Centaury) plants have an important place in the flora of Turkey after Rosa damascena Mill (rose).
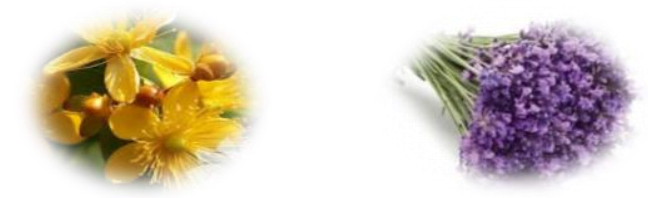

Hypericum perforatum Lavandula officinalis

Plant extracts are being produced by mainly conventional techniques such as hydro and steam distillation and solvent extraction methods which have several disadvantages. In these methods, heat-sensitive compounds can easily be destroyed while performing the extraction and the quality of oil extracts is extremely impaired $(6,7)$.
In recent years, supercritical carbon dioxide $\left(\mathrm{scCO}_{2}\right)$ extraction has been started to be used as an alternative technique for the extraction of essential oil and extracts of plants since it has several advantages such as non-toxic, nonexplosive and readily available, and solvent-free production (7).

In this study, extracts of lavender and centaury plants grown in Mersin region were extracted by $\mathrm{SCCO}_{2}$ extraction method which is eco-friendly. Antibacterial and antioxidant properties of the obtained extracts were examined.

\section{MATERIAL AND METHODS}

\section{Plant material}

Lavender and centaury plants grown in Mersin region from Turkey were dried in the air without exposure to sunlight and stored at room temperature.

\section{Supercritical $\mathrm{CO}_{2}$ Extraction}

10 grams of milled flowers of lavender and centaury plants were loaded into a $100 \mathrm{~mL}$ stainless steel extraction vessel, which was then pressurized via a $\mathrm{CO}_{2}$ pump (ISCO Model 260D Syringe pump). Plants were extracted by $\mathrm{scCO}_{2}$ extraction system as seen in Scheme 1. $(P=145$ bar, $\mathrm{T}=45^{\circ} \mathrm{C}$ for lavender and $\mathrm{P}=150$ bar, $\mathrm{T}=40$ ${ }^{\circ} \mathrm{C}$ for centaury).

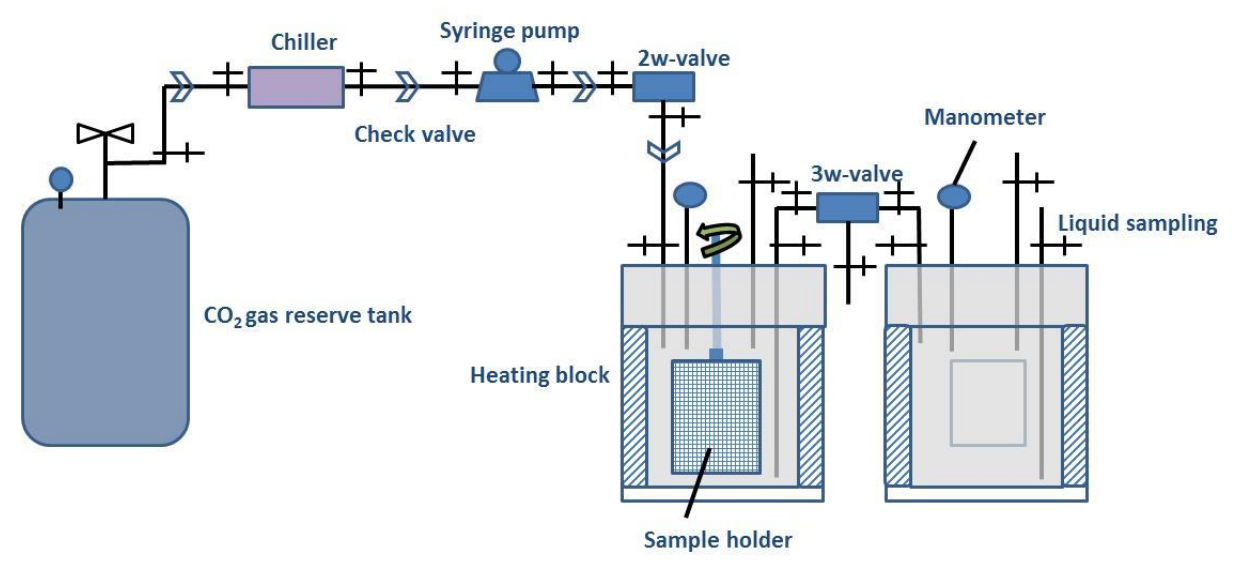

Scheme 1. Supercritical $\mathrm{CO}_{2}$ extraction system.

\section{Chemical Analysis}

The chemical composition of the lavender and centaury extracts were analyzed by Gas Chromatography-Mass Spectrometry (GC-MS) and GC. The GC-MS analyses were performed on a Agilent Technologies 7890 A GC system with a HP-5MS capillary column (30.0 m x $0.25 \mathrm{~mm}$; film thickness $0.25 \mu \mathrm{m}$ ) coupled with an Agilent Technologies 5975 mass selective detector. Injector and detector temperatures were set to $220{ }^{\circ} \mathrm{C}$ and $260{ }^{\circ} \mathrm{C}$, respectively for operating GC analysis. The helium flow rate was $1.0 \mathrm{~mL} / \mathrm{min}$ for GC.

\section{Antioxidant Activity Assay}

Six different concentrations (3-9 $\mathrm{mg} / \mathrm{mL}$ ) of the lavender and centaury extracts were prepared for antioxidant activity measurement. 1,1-Diphenyl2-picrylhydrazine (DPPH) radical was used to determine the radical scavenging effect. Different concentrations of plant extracts were prepared with equal volumes of ethanolic solution of DPPH $(100 \mu \mathrm{L})$ and incubated in the dark for $1 / 2$ hour. The experiments were carried out at three different time intervals. Butylhydroxytoluene (BHT) was used as standard controls. The absorbance was then measured by a UV-visible spectrophotometer at a wavelength of $515 \mathrm{~nm}$. DPPH solution was used as control $\left(A_{0}\right)$. The radical scavenging effect was calculated as inhibition percentage from the following formula: 
DPPH scavenging effect $(\%)=\left[\left(A_{0}-A_{1}\right) / A_{0}\right]$ $\times 100$

(Eq. 1)

$A_{0}=$ absorbance of control (DPPH solution), $A_{1}=$ Absorbance measured in the presence of sample.

\section{Antibacterial Activity Assay}

For antimicrobial activity experiments, bacteria were obtained from the Microbiology Laboratory of the Biology Department of the Faculty of Science and Letters of Mersin University. Three strains of gram-positive bacteria Bacillus subtilis, Staphylococcus aureus and Streptococcus pneumoniae were used for Nutrient Agar (NA) media. Three strains of gram negative bacteria Escherichia coli, Klebsiella pneumoniae, Pseudomonas aeruginosa were used for Eosin Methylene-blue lactose sucrose agar (EMB) media. The diffusion method was used to determine the antimicrobial effect of plant extracts. Mueller-Hinton Agar (MHA) was used as a nutrient in this method, which is based on the inhibition of the development of microorganisms in the field where the substance to be tested diffused in the agar. MHA nutrient was prepared by dissolving $2 \mathrm{~g}$ of meat infusion, $17.5 \mathrm{~g}$ of casein hydrolyzate, $1.5 \mathrm{~g}$ of starch and $17 \mathrm{~g}$ of agar in $1000 \mathrm{~mL}$ distilled water ( $\mathrm{pH}$ 7.2).

Prior to the test, the colonies in cultures incubated for 18-24 hours in Nutrient Agar were solubilized using physiological saline in equal turbidity to 0.5 McFarland standard solution. Then, the prepared solution was diluted to contain about $1-5 \times 10^{6}$ bacteria and used as inoculum. $100 \mu \mathrm{L}$ of the prepared inoculum was transferred to the MHA surface and spread and immediately afterwards $10 \mathrm{~mm}$ holes were drilled in the medium. After transferring $200 \mu \mathrm{L}$ per well of plant extracts (50 $\mathrm{mg} / \mathrm{mL}$ ), the petrel was incubated at $37^{\circ} \mathrm{C}$ for 24 48 hours. At the end of the incubation, formation of open zone (area where microorganism could not grow) was observed around the holes where plant extracts were transferred. The resulting zone diameters are measured in $\mathrm{mm}$. All tests were performed in 3 repetitions and the standard deviation of the zone diameters was calculated (Figure 1). After adding the extracts in cream formulation as preservatives, antibacterial activity measurements were performed at the first month $\left(t_{0}\right)$, third month $\left(t_{1}\right)$ and 6 th month $\left(t_{2}\right)$ (Figures 2 and 3 ).

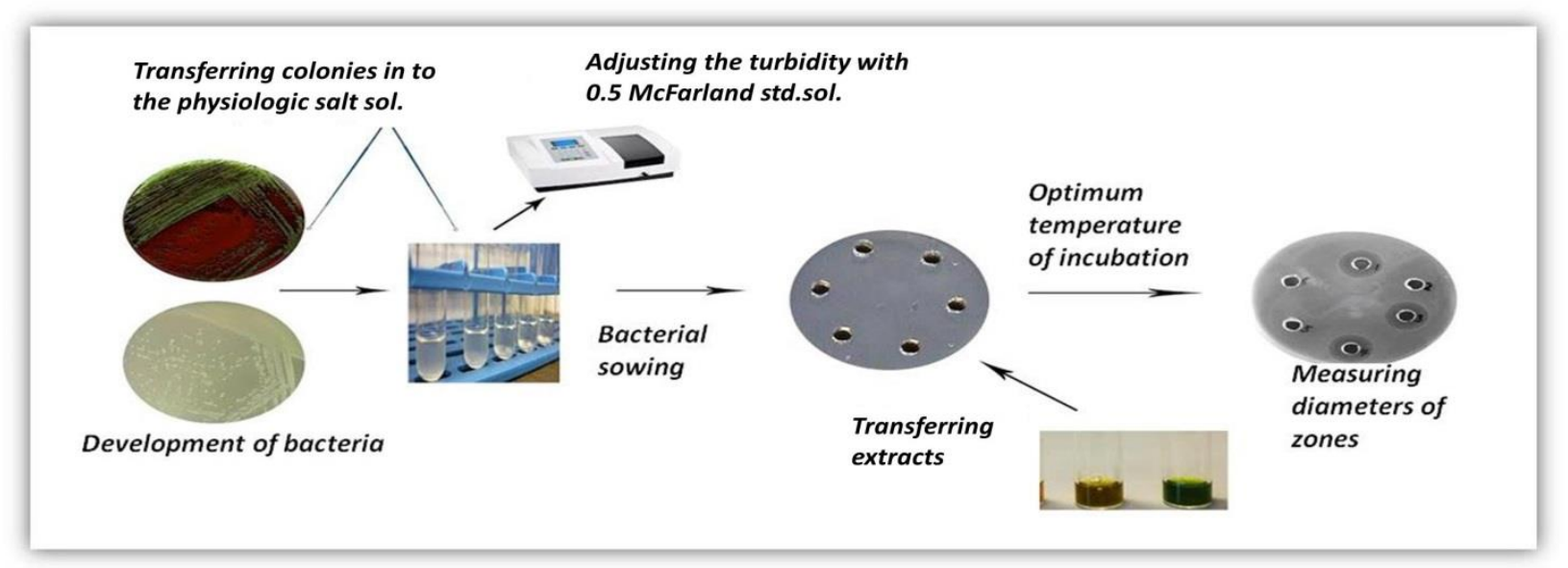

Figure 1. Antibacterial activity determination method

\section{RESULTS AND DISCUSSION}

\section{Extraction Yield}

Lavender and centaury plants were extracted by $\mathrm{SCCO}_{2}$ extraction system. The extraction yields for lavender and centaury were $4.68 \%$ and $3.83 \%$, respectively.

\section{Chemical Composition}

Main chemical compositions of centaury and lavender extracts are given in Tables 1 and 2 , respectively. 
Table 1. Main composition of the supercritical $\mathrm{CO}_{2}$ extract of centaury.

\begin{tabular}{ll}
\hline Compound & Content (\%) \\
\hline Menthone & 0.44 \\
(+)-Isomenthone & 0.21 \\
L-Menthol & 2.42 \\
Caryophyllene oxide & 1.38 \\
Cyclotetradecane & 1.82 \\
3-Tetradecene & 3.80 \\
2-Pentadecanone & 1.29 \\
7-Hexadecene & 2.86 \\
1,2-Benzenedicarboxylic acid & 13.43 \\
Phytol & 7.12 \\
n-Tricosane & 1.27 \\
n-Octacosane & 1.47 \\
n-Dotriacontane & 1.36 \\
n-Tetratriacontane & 22.61 \\
Hexacosanal & 4.19 \\
\hline
\end{tabular}

Table 2. Main composition of the supercritical $\mathrm{CO}_{2}$ extract of lavender.

\begin{tabular}{ll}
\hline Compound & Content (\%) \\
\hline 1-Octen-3-ol & 0.28 \\
1,8-Cineole & 1.15 \\
a-Terpinene & 0.17 \\
Linalool & 36.20 \\
Camphor & 8.03 \\
Borneol & 6.65 \\
Lavandulol & 0.49 \\
Terpinen-4-ol & 2.13 \\
a-Terpineol & 0.70 \\
Linalyl acetate & 19.37 \\
Lavandulyl acetate & 1.32 \\
$\beta$-Farnesene & 3.53 \\
Germacrene D & 0.88 \\
a-Bisabolol & 1.06 \\
\hline
\end{tabular}

\section{Antioxidant Activity}

The free radical scavenging activities of centaury and lavender extracts are given in Tables 3 and 4 , respectively. The inhibition rates of the plant extracts were examined. It was observed that as the inhibition times and concentration increased, the radical scavenger activity increased.

Table 3. DPPH scavenging effects of centaury (inhibition \%).

\begin{tabular}{lccccccc}
\hline $\begin{array}{l}\text { Concentration/ } \\
\text { time }\end{array}$ & $\begin{array}{c}\mathbf{3} \\
\mathbf{m g} / \mathbf{m L}\end{array}$ & $\begin{array}{c}\mathbf{4} \mathbf{m g} / \mathbf{m L} \\
\mathbf{m g} / \mathbf{m L}\end{array}$ & $\begin{array}{c}\mathbf{6} \\
\mathbf{m g} / \mathbf{m L}\end{array}$ & $\begin{array}{c}\mathbf{7} \\
\mathbf{m g} / \mathbf{m L}\end{array}$ & $\begin{array}{c}\mathbf{8} \\
\mathbf{m g} / \mathbf{m L}\end{array}$ & $\begin{array}{c}\mathbf{9} \\
\mathbf{m g} / \mathbf{m L}\end{array}$ \\
\hline 0 $\mathrm{min}$. & 80.7 & 81.7 & 83.7 & 87.8 & 89.6 & 91.3 & 93.3 \\
15 min. & 85.0 & 82.6 & 84.8 & 87.9 & 90.7 & 92.1 & 94.2 \\
30 min. & 86.7 & 87.1 & 88.2 & 89.0 & 91.4 & 96.2 & 97.1 \\
\hline
\end{tabular}


Table 4. DPPH scavenging effects of lavender (inhibition \%).

\begin{tabular}{|c|c|c|c|c|c|c|c|}
\hline $\begin{array}{l}\text { Concentration/ } \\
\text { Time }\end{array}$ & $\begin{array}{c}3 \\
\mathrm{mg} / \mathrm{mL}\end{array}$ & $\begin{array}{c}4 \\
\mathrm{mg} / \mathrm{mL}\end{array}$ & $\begin{array}{c}5 \\
\mathrm{mg} / \mathrm{mL}\end{array}$ & $\begin{array}{c}6 \\
\mathrm{mg} / \mathrm{mL}\end{array}$ & $\begin{array}{c}7 \\
\mathrm{mg} / \mathrm{mL}\end{array}$ & $\begin{array}{c}8 \\
\mathrm{mg} / \mathrm{mL}\end{array}$ & $\begin{array}{c}9 \\
\mathrm{mg} / \mathrm{mL}\end{array}$ \\
\hline $0 \mathrm{~min}$. & 0 & 7.9 & 8.7 & 14.9 & 12.2 & 21.8 & 23.8 \\
\hline $15 \mathrm{~min}$. & 4.3 & 14.4 & 11.6 & 21.6 & 24.0 & 32.3 & 35.6 \\
\hline $30 \mathrm{~min}$. & 7.3 & 17.9 & 13.8 & 26.2 & 28.5 & 37.8 & 40.9 \\
\hline
\end{tabular}

\section{Antibacterial Activity}

Antibacterial activity of plants extracts was determined with the zone diameters by the agar disc diffusion method, given in Table 5. Gramnegative bacteria Escherichia coli, Klebsiella pneumoniae, and Pseudomonas aeruginosa are pathogenic bacteria that cause diseases. Gram- positive bacteria Bacillus subtilis, Staphylococcus aureus and Streptococcus pneumoniae are known as non-noxious bacteria. According to the results, the plant extracts inhibit the formation of grampositive and gram-negative bacteria. Antibacterial effect of lavender extract was higher than that of the centaury extract.

Table 5. Antibacterial activity test results of plant extracts.

\begin{tabular}{ccc}
\hline BACTERIA & Gram Lavender & Centaury \\
$(\mathbf{m m})$ & $(\mathbf{m m})$
\end{tabular}

\begin{tabular}{llll}
\hline Streptococcus pneumoniae & + & $32.7 \pm 2.5$ & $12.0 \pm 1.0$ \\
Escherichia coli & - & $24.7 \pm 0.6$ & $10.7 \pm 0.6$ \\
Staphylococcus aureus & + & $37.0 \pm 1.7$ & $11.7 \pm 0.6$ \\
Klebsiella pneumoniae & - & $25.7 \pm 1.5$ & $10.3 \pm 0.6$ \\
Pseudomonas aeruginosa & - & $18.7 \pm 1.2$ & $10.0 \pm 1.0$ \\
Bacillus subtilis & + & $31.3 \pm 1.2$ & $14.3 \pm 1.5$ \\
\hline
\end{tabular}

The Use of Plant Extracts in Cosmetic

\section{Creams}

The extracts of lavender and centaury plants were added to standard cream formulations as preservatives with a ratio of $2 \%, 3 \%$ and $4 \%$ and their antibacterial properties were examined. Phenoxyethanol was used as a preservatives for the same purpose of preserving the same amount of creams for comparison. Finally the nonprotective cream is prepared. Samples were taken from the prepared creams at the first month $\left(t_{0}\right)$, third month $\left(t_{1}\right)$ and 6 th month $\left(t_{2}\right)$ for measurements of the number of the bacteria (Table 6).

Table 6. Bacterial formation values of different time and concentrations in creams with and without preservatives.

\begin{tabular}{|c|c|c|c|c|c|c|c|c|c|c|c|c|}
\hline & \multirow{2}{*}{\multicolumn{3}{|c|}{$\begin{array}{c}\text { Cream with } \\
\text { Lavender Extract } \\
\text { Concentration }\end{array}$}} & \multirow{2}{*}{\multicolumn{3}{|c|}{$\begin{array}{c}\text { Cream with } \\
\text { Centaury Extract } \\
\text { Concentration } \\
\end{array}$}} & \multirow{2}{*}{\multicolumn{3}{|c|}{$\begin{array}{c}\text { Cream with } \\
\text { preservatives } \\
\text { Concentration }\end{array}$}} & \multirow{3}{*}{$\begin{array}{l}\text { Cream without } \\
\text { preservatives }\end{array}$} \\
\hline & & & & & & & & & & & & \\
\hline & & & $2 \%$ & $3 \%$ & $4 \%$ & $2 \%$ & $3 \%$ & $4 \%$ & $2 \%$ & $3 \%$ & $4 \%$ & \\
\hline \multirow{3}{*}{$\begin{array}{l}\text { Nutrient } \\
\text { Agar (NA) }\end{array}$} & \multirow{6}{*}{$\sum_{\models}^{\rightleftarrows}$} & $t_{0}$ & 10 & 6 & 1 & 7 & 3 & 0 & 0 & 0 & 0 & 0 \\
\hline & & $t_{1}$ & 0 & 0 & 0 & 0 & 0 & 0 & 0 & 0 & 1 & 4 \\
\hline & & $t_{2}$ & 0 & 0 & 0 & 0 & 0 & 0 & 1 & 0 & 185 & 944 \\
\hline \multirow{3}{*}{ EMB Agar } & & $t_{0}$ & 0 & 0 & 0 & 0 & 0 & 0 & 0 & 0 & 0 & 0 \\
\hline & & $t_{1}$ & 0 & 0 & 0 & 0 & 0 & 0 & 0 & 0 & 0 & 10 \\
\hline & & $t_{2}$ & 0 & 0 & 0 & 0 & 0 & 0 & 0 & 0 & 0 & 896 \\
\hline
\end{tabular}

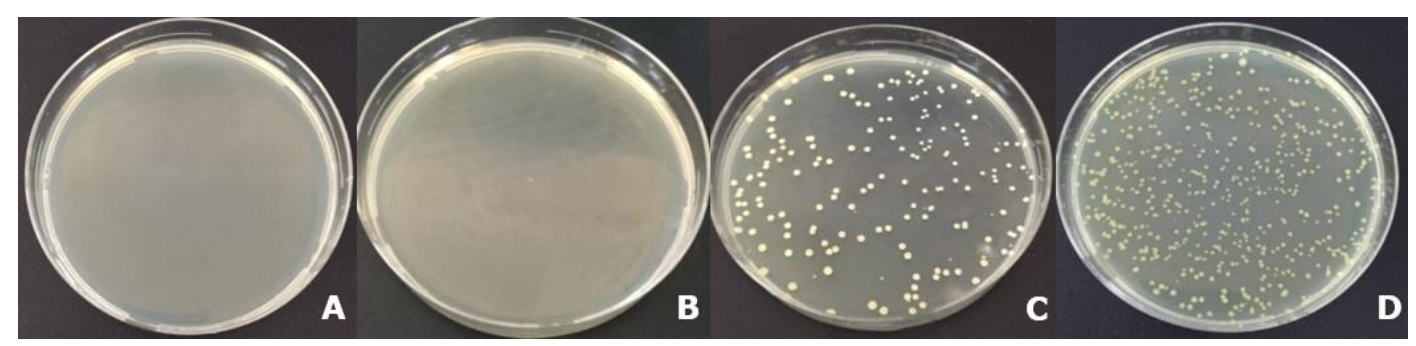

Figure 2. Bacterial growth on Nutrient Agar (NA) medium at the end of the $6^{\text {th }}$ month $\left(t_{2}\right)$ of cream samples added to $4 \%$ plant extract, A; cream with lavender extract, B; cream with centaury extract, C; cream with preservative, D; cream without preservative. 


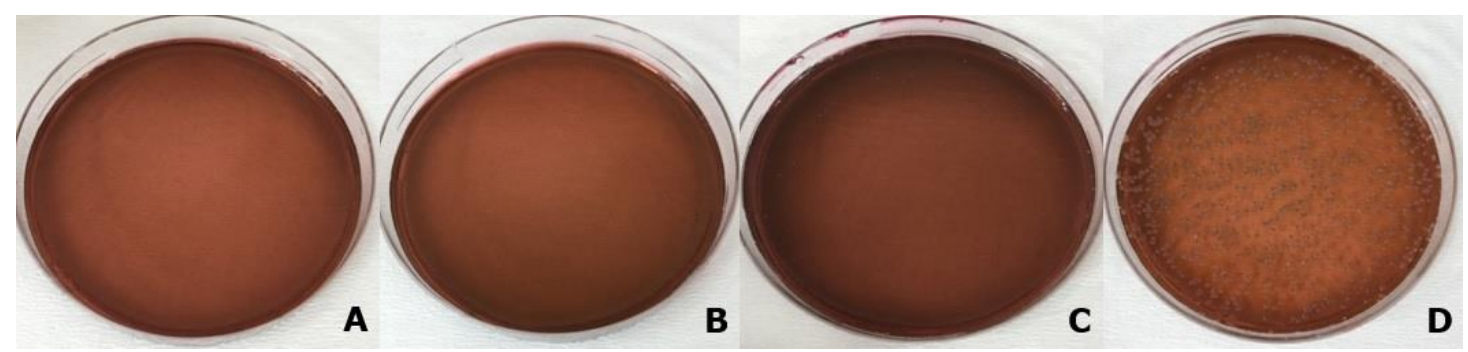

Figure 3. Bacterial growth on Eosin Methylene-Blue. Lactose Sucrose Agar (EMB) medium at the end of the $6^{\text {th }}$ month $\left(t_{2}\right)$ of cream samples added to $4 \%$ plant extract, $\mathbf{A}$; cream with lavender extract, B; cream with centaury extract, $\mathbf{C}$; cream with preservative, $\mathbf{D}$; cream without preservative.

\section{CONCLUSIONS}

Creams are the cosmetic products used frequently in our daily life. In addition, properties such as preservatives, moisturizers and nutrients, these products must be suitable for long-term and daily use in terms of microbiology. Due to the substances present in the composition of cosmetic products, microorganisms that occur during or after production cause contamination. Metabolites resulting from contamination are known for their damages to the skin. In recent years, plant extracts have started to be used instead of chemical preservatives used to prevent contamination. While the upper limit of the number of non-pathogenic microorganisms that cosmetic products may contain is $10^{3}$, it is known that it should not contain pathogenic microorganisms that poses a danger to human health (8-10).

In this study, the extracts of lavender and centaury plants were also used in cosmetic cream formulas as protectives. It has been determined that the resulting extracts have significant effects even after 6 months passed as seen in Figures 2 and 3 .

According to the results, $\mathrm{scCO}_{2}$ extraction is useful technique for extraction of essential oils from lavender and centaury. Moreover, these extracts can be used in cosmetics as preservatives in creams. Due to their antioxidant and antibacterial effects, the extracts may also be used in pharmaceutical and food industries.

\section{ACKNOWLEDGEMENTS}

This project was funded by Mersin University (Project No: BAP 2016-2-TP2-1950) and was partially presented as poster presentations at International Chemistry \& Biology Conference'18, Sharm El Sheikh, Egypt and 2. International Cosmetic Cogress, 2018, Antalya, Turkey. We also thank to Levent Kahrıman (Manager of Laber Organic Cosmetics R \& D Production, Marketing, Industry Trade Co.) for providing raw materials and cream (Brand of IVA Natura-Anatolian Plants Series) formulations support.

\section{REFERENCES}

1. Hammer KA, Carson CF, Riley TV. Antimicrobial activity of essential oils and other plant exracts. Jourmal of Applied Microbiology. 1999; (86): 985-90.

2. Prabuseenivasan S, Jayakumar M, Ignacimuthu S. In vitro antibacterial activity of some plant essential oils. BMC Complementary and Alternative Medicine. 2006; (6):39.

3. Wang $L$, Weller $C L$. Recent advances in extraction of nutraceuticals from plants. Trends in Food Science \& Technology. 2006; (17): 300-12.

4. Zou Y, Lu Y, Wei D. Antioxidant Activity of a Flavonoid-Rich Extract of Hypericum perforatum L. In Vitro. J. Agric. Food Chem. 2004; (52): 5032-9.

5. Robu S, Aprotosoaie AC, Miron A, Cioanca O, Stanescu U, Hancianu M. In Vitro Antioxidant Activity of Ethanolic Extracts from Some Lavandula Species Culti Ated in Romania. Farmacia. 2012; (60): 3.

6. Danh TL, Han LN, Triet NDA, Zhao J, Mammucari R, Foster N. Comparison of Chemical Composition, Antioxidant an Antimicrobial Activity of Lavender (Lavandula angustifolia L.) Essential Oils Extracted by Supercritical $\mathrm{CO}_{2}$, Hexane and Hydrodistillation. Food Bioprocess Technol. 2003; (6): 3481-9.

7. Pourmortazavi SM, Hajimirsadeghi SS. Supercritical fluid extraction in plant essential and volatile oil analysis. J. Chromatogr. A. 2007; (1163): 2-24.

8. Çelik GY and Çelik E, Antimicrobial Properties of Plant Essential Oils. Orlab On-Line Journal of Microbiology. 2007; 5(2): 1-6.

9. Underwood E et al. Ecology of Microorganisms as It Affects the Pharmaceutical Industry. Pharmaceutical Microbiology. 6th ed. Oxford: Blackwell Science. 1998, 339-54.

10. Smart R and Spooner DF. Microbiological Spoilage in Pharmaceuticals and Cosmetics. J. Soc. Cosmet. Chem. 1972; (23): 721-37. 